\title{
Pengembangan Media Permainan Mipon's Daily untuk Meningkatkan Kemampuan Berhitung Anak
}

\author{
Nila Mayang Sari ${ }^{1}$, Elindra Yetti ${ }^{2}$, Hapidin ${ }^{3}$ \\ Pendidikan Anak Usia Dini, Universitas Negeri Jakarta \\ DOI: $10.31004 /$ obsesi.v4i2.428
}

\begin{abstract}
Abstrak
Kemampuan berhitung merupakan kemampuan dasar anak dalam mempelajari matematika terkait pemahaman mengenal bilangan. Penelitian ini bertujuan untuk mengembangkan sebuah media permainan dan mengetahui efektivitasnya untuk meningkatkan kemampuan berhitung anak usia 5-6 tahun. Media permainan ini disebut Mipon's Daily yang dirancang melalui aplikasi powerpoint yang disesuaikan dengan tingkat perkembangan anak. Penelitian ini dilakukan di Kabupaten Lima Puluh Kota, Sumatera Barat. Uji efektivitas media permainan Mipon's Daily menggunakan uji t-berpasangan. Responden dalam penelitian sebanyak dua puluh orang anak di TK Restu Ibu Ketinggian. Berdasarkan hasil perhitungan, terdapat peningkatan rata-rata sebelum diberikan perlakuan dengan setelah diberikan perlakuan. Diketahui hasil $t$ hitung juga lebih besar dibandingkan dengan nilai $t$ tabel sehingga $\mathrm{HO}$ ditolak, berarti dapat disimpulkan bahwa terdapat perubahan yang signifikan antara sebelum menggunakan media permainan Mipon's Daily (pretest) dengan setelah menggunakan media permainan Mipon's Daily (posttest). Jadi, produk yang dikembangkan efektif digunakan dalam meningkatkan kemampuan berhitung anak usia 5-6 tahun.

Kata Kunci: kemampuan berhitung; anak usia dini; media permainan mipon's daily
\end{abstract}

\begin{abstract}
The ability to count is the basic ability of children to learn mathematics related to understanding numbers. This study aims to develop a media game and find out its effectiveness to improve the numeracy skills of children aged 5-6 years. This game media is called Mipon's Daily which is designed through a powerpoint application that is adjusted to the level of child development. This research was conducted in Lima Puluh Kota District, West Sumatra. The effectiveness test of Mipon's Daily game media was conducted using the one-group pretest-posttest experimental method using the ADDIE development model. Respondents in the study were twenty children in Restu Ibu Keinggian Kindergarten. Based on the calculation results, there is an increase in the average before treatment is given after treatment is given. It is known that the result of $t$ count is also greater than the value of $t$ table so $\mathrm{HO}$ is rejected, meaning that it can be concluded that there are significant changes between before using the media game Mipon's Daily (pretest) and after using the media game Mipon's Daily (posttest). So, the product developed is effectively used in increasing the numeracy ability of children aged 5-6 years.
\end{abstract}

Keywords: Counting Ability, Early Childhood, Mipon's Daily Game Media

Copyright (c) 2020 Nila Mayang Sari, Elindra Yetti, Hapidin

$\triangle$ Corresponding author:

Email Address : mayangsarinila08@gmail.com (Jln. Pemuda 1, Rawamangun, Jakarta Timur)

Received 12 January 2020, Accepted 13 February 2020, Published 16 February 2020 


\section{PENDAHULUAN}

Pada era teknologi saat ini, pendidikan anak usia dini perlu perhatian secara menyeluruh dari semua pihak. Tidak hanya peranan orang tua dan guru melainkan juga pemerintah. Hal ini diatur dalam Peraturan Pemerintah Nomor 2 Tahun 2018 tentang Standar Pelayanan Minimal (SPM) yang menekankan pada pentingnya peran pemerintah dalam memberikan pelayanan pendidikan anak usia dini (Kementerian Pendidikan dan Kebudayaan, 2018). Anak membutuhkan pendidikan karena mereka merupakan pilar bangsa yang akan mengambil tampuk kepemimpinan dimasa yang akan datang. Oleh karena itu, untuk mewujudkan hal tersebut anak usia dini perlu diberikan pendidikan yang tepat agar berkembang secara optimal.

Usia dini dikenal dengan masa golden age yang merupakan masa emas bagi anak yang berumur 0-6 tahun. Pada masa ini, anak berkembang sangat pesat sesuai dengan perkembangan otaknya yang hampir mencapai $80 \%$ (Suryana, 2018). Untuk itu anak memerlukan stimulasi dan intervensi yang tepat dalam berkembang. Disamping itu, orangtua dan guru seyogyanya harus lebih peka dan telaten dalam mencermati setiap tahapan perkembangan dasar seorang anak. Perkembangan anak tidak hanya ditekankan pada satu aspek saja, melainkan harus mencakup semua aspek. Aspek-aspek ini harus dikembangkan secara menyeluruh karena sifatnya berkesinambungan. Salah satu aspek yang sangat penting adalah aspek perkembangan kognitif.

Perkembangan kognitif erat kaitannya dengan kecerdasan logika matematika. Menurut Hapidin, 2015, pp. 45-46, logika matematika merupakan suatu proses kognitif yang berkaitan dengan kemampuan seseorang dalam menyimpulkan sesuatu melalui cara tertentu. Kegiatan matematika dapat dipelajari anak melalui kehidupan sehari-harinya seperti: kegiatan membilang, menjumlah, mengurangi, mengenal angka, membandingkan jumlah, serta menyimpulkan data. Melalui hal ini, dapat digambarkan bahwa anak memerlukan kemampuan berfikirnya dalam merespon dan mempelajari kegiatan tersebut.

Hasil survei yang dilakukan Programme for International Student Assessment (PISA) pada tahun 2015 tentang sistem pendidikan di Indonesia dalam bidang matematika masih tergolong rendah. Survei tersebut menunjukkan bahwa Indonesia masih berada di bawah rata-rata negara-negara OECD seperti Amerika, Kanada, Inggris bahkan Negara Asia Tenggara seperti Singapura, Vietnam, dan Thailand (Gurria Angel, 2015). Hal ini tentunya bukanlah kesalahan mutlak yang dilakukan oleh peserta didik, melainkan perlu dijadikan tombak dalam upaya mengejar ketertinggalan di ruang lingkup internasional. Pemerintah juga perlu menilik kembali tentang pengoptimalan sarana-prasarana pembelajaran dan pendidik yang berkualitas serta kompeten di bidangnya.

Pada hakikatnya pendidikan terjadi secara berkesinambungan, mulai dari prasekolah, SD, SMP, SMA hingga Perguruan Tinggi. Perlunya penelaahan lebih jauh tentang proses pendidikan mulai dari dasar yaitu pendidikan anak usia dini. Ini bertujuan agar terciptanya generasi yang berkualitas dan mampu bersaing dengan perkembangan zaman dimasa yang akan datang. Begitu juga dengan guru, harus memberikan konsep belajar yang jelas agar tercapainya tujuan pendidikan yang tepat sasaran. Salah satunya menurut (Zosh et al., 2017) adalah playful learning (pembelajaran yang menyenangkan) yang dapat dilakukan melalui permainan.

Selain itu, kemampuan berhitung juga merupakan bagian dari matematika. Menurut Aunio (2019) kemampuan berhitung merupakan pijakan awal anak dalam mempelajari matematika di sekolah. Anak perlu memahami kegiatan berhitung sebelum bisa memahami kegiatan lain dalam matematika.

Kemampuan berhitung berkaitan dengan bilangan yang di dalamnya terdapat kegiatan menyebutkan bilangan, mengidentifikasi bilangan, membandingkan serta mengoperasikan bilangan (Raghubar \& Marcia A. Barnes, 2016). Dengan mempelajari kemampuan berhitung, maka akan memudahkan anak dalam mempelajari matematika di sekolah formal. Mengingat begitu pentingnya kemampuan berhitung, maka harus 
diperkenalkan sejak dini melalui berbagai media, metode dan strategi yang tepat agar anak dapat menerimanya dengan mudah.

Berdasarkan hasil studi pendahuluan yang dilakukan melalui wawancara dengan kepala sekolah TK Restu Ibu Ketinggian dijelaskan bahwa, terdapat beberapa anak yang masih memiliki kemampuan yang rendah dalam berhitung. Mereka masih kesulitan dalam memahami bilangan yang disebutkan oleh guru. Hal ini terlihat dari beberapa anak yang salah dalam menunjukkan jumlah jari tangan saat guru menyebutkan sebuah bilangan. Anak belum mampu dalam menyebutkan nama bilangan yang ditunjuk guru. Pada saat berhitung anak menyebutkan bilangan dengan cepat tanpa memperhatikan jari tangan yang dihitungnya, hal ini dikarenakan anak baru mampu menghafal deretan angka tanpa mengetahui konsep dari bilangan itu sendiri. Sedangkan menurut (Rosalind and Karen K. Lind, 2013) anak yang berumur di atas empat atau lima tahun telah masuk ke fase berhitung rasional. Dimana anak sudah tidak menghafal angka lagi melainkan mengetahui konsep dari bilangan yang disebutkan.

Selain itu, dalam pengenalan konsep berhitung guru menggunakan beberapa media seperti lidi dan jari tangan. Tetapi media ini belum mampu untuk memaksimalkan kemampuan anak dalam berhitung karena anak kurang tertarik dan mudah bosan dengan media yang ada. Sesuai hasil wawancara dengan kepala sekolah, diketahui anak-anak sering terpapar gadget di luar lingkungan sekolah. Sehingga, hal ini menimbulkan ketidaktertarikan anak dengan media yang ada di sekolah karena anak telah terbiasa dengan media interaktif yang dapat diakses melalui gadget mereka. Jika hal ini terus berlanjut, maka anak akan mengalami kesulitan dalam memahami konsep berhitung. Sesuai dengan penelitian dari Aunio dan Mononen (2017) yang mengungkapkan bahwa anak-anak yang memiliki masalah dalam pembelajaran matematika di TK maka mereka akan terus tertinggal di tahun-tahun sekolah berikutnya.

B. Ramani, Geetha, Emily N. Daubert dan Nicole R. Scalise (2019) dalam penelitiannya menyebutkan bahwa kemampuan matematika anak usia dini dapat ditingkatkan melalui permainan tradisional maupun permainan komputer. Hal ini dibuktikan oleh penelitian dari Lestariningrum, Anik dan Handini (2017) yang mengemukakan bahwa permainan tradisional congklak dan engklek dapat mengembangkan kecerdasan logis matematis anak usia 5-6 tahun. Penelitian ini juga didukung oleh Laily \& Jalal (2019) yang menjelaskan bahwa konsep matematika awal tentang bilangan dan geometri pada anak mampu ditingkatkan melalui media permainan papan semat. Begitu juga dengan penelitian dari Malapata, Wijayaningsih, Kristen, \& Wacana (2019) yang menemukan bahwa media lumbung hitung dapat meningkatkan kemampuan berhitung anak usia dini.

Meskipun permainan tradisional dapat meningkatkan kemampuan matematika pada anak, akan tetapi pembelajaran berbasis game digital dinyatakan lebih efektif (Pei, 2018). Hal ini dibuktikan melalui penelitian dari Kermani (2017) yang berhasil menemukan bahwa permainan matematika yang berbasis komputer dapat meningkatkan pemahaman anakanak terhadap pengertian jumlah dengan fasilitas dan dukungan guru dalam mengajar. Begitu juga dengan riset dari Choirun Nisa (2012, p. 91) yang menambahkan bahwa media digital dapat dijadikan sebagai alternatif pembelajaran pada anak usia dini karena dilengkapi dengan unsur warna, musik dan karikatur yang sesuai dengan kesukaan anak.

Sekarang ini, permainan digital tidak hanya dirancang melalui aplikasi adobeflash saja melainkan juga bisa melalui aplikasi microsoft powerpoint. Penelitian dari (Nuriani, Soemantri, \& Sutrisno, 2016, p. 125) menyatakan bahwa microsoft powerpoint dapat meningkatkan kemampuan kognitif anak. Penelitian ini memberikan materi pembelajaran melalui slide yang ditampilkan dengan bantuan proyektor. Pembelajaran ini memudahkan anak dalam menerima informasi, meningkatkan semangat serta menghasilkan pembelajaran yang bermakna. Hal ini dikarenakan, powerpoint memiliki kelebihan dalam penyajiannya, terutama dalam hal warna, huruf, dan animasi. 
Penelitian lain dari Philips Parette, Jack J. Hourcade, Nichole M.Boeckmann, \& Craig Blum (2008) menjelaskan bahwa media powerpoint dapat meningkatkan kemampuan literasi anak terutama dalam hal membaca. Dalam penelitian ini, guru menggabungkan media powerpoint dengan direct instruction (instruksi langsung). Ketika guru menampilkan gambar dan suara melalui proyektor, guru juga bertanya langsung pada anak tentang apa yang ditampilkan. Jadi, media powerpoint disini berfungsi sebagai alat untuk menampilkan gambar, bacaan dan suara dari sebuah kata yang dikenalkan pada anak.

Dari beberapa penelitian di atas, dijelaskan bahwa media pembelajaran yang berbasis digital mampu mengoptimalkan pembelajaran anak usia dini. Terkait hal tersebut, peneliti ingin merancang sebuah media permainan digital dengan menggunakan aplikasi microsoft powerpoint. Penelitian sebelumnya menunjukkan bahwa pemanfaatan aplikasi ini masih terbatas dalam hal menampilkan slide yang hanya berisi gambar dan suara dengan bantuan proyektor. Sedangkan, penelitian yang dilakukan adalah menciptakan sebuah media permainan yang mengandung unsur interaktif.

Permainan yang dirancang melalui microsoft powerpoint ini mengandung alur cerita tentang kegiatan yang dilakukan anak setiap hari, juga dilengkapi animasi serta backsound yang jelas, mengandung konsep yang berfokus pada pemahaman berhitung anak, dan mudah untuk diintegrasikan dengan tema yang ada. Perancangan media permainan ini tidak membutuhkan biaya yang mahal karena diciptakan melalui aplikasi powerpoint yang telah ada di komputer. Media permainan ini dinamakan dengan media permainan Mipon's Daily dengan tujuan meningkatkan kemampuan berhitung anak usia 5-6 tahun.

\section{METODOLOGI}

Penelitian ini menggunakan pendekatan pre-experimental designs dengan one group pretest-posttest design. Pelaksanaan eksperimen dalam penelitian ini hanya menggunakan satu kelompok saja dan tidak menggunakan kelas kontrol. Untuk model pengembangan dalam penelitian ini menggunakan model pengembangan ADDIE dari Robert Maribe Branch. Model ADDIE sesuai untuk mengembangkan produk pendidikan dan sumber belajar karena langkah-langkahnya dijelaskan secara rinci dan sederhana yang terdiri dari lima tahapan yaitu Analysis, Design, Development, Implementation dan Evaluation.

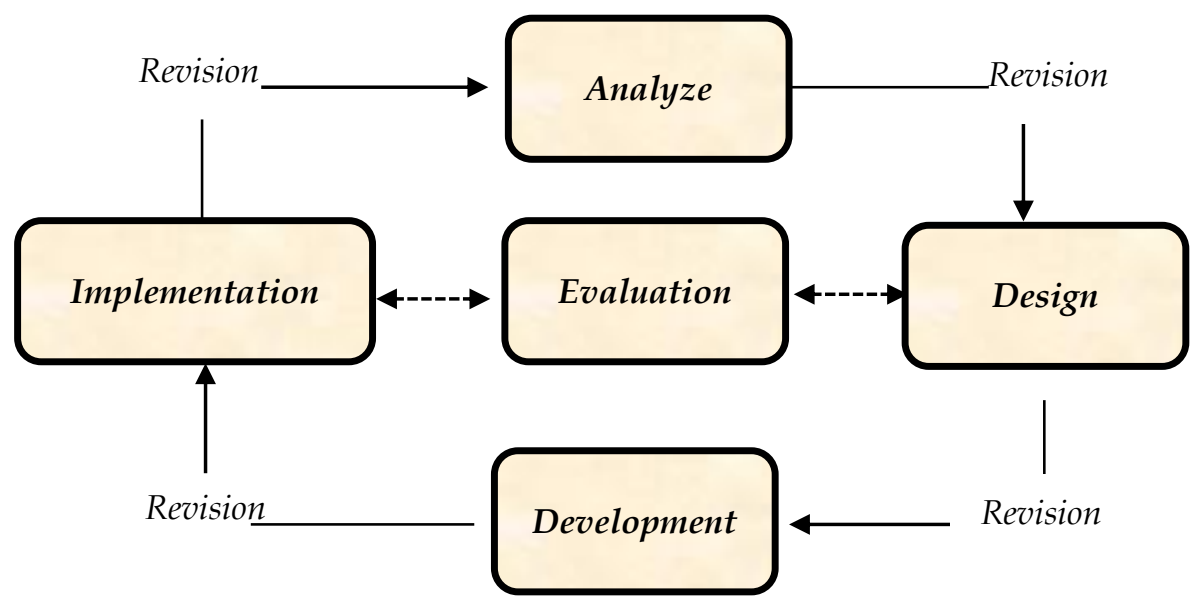

Gambar 01. Model Pengembangan ADDIE

Tahap analysis, peneliti melakukan analisis kebutuhan melalui studi literatur dan studi pendahuluan. Peneliti melakukan studi literatur dengan mengkaji beberapa jurnal baik nasional maupun internasional serta buku-buku yang terkait dengan permasalahan kemampuan berhitung anak. Untuk studi pendahuluan, peneliti melakukan observasi di TK Restu Ibu Ketinggian dengan melihat kemampuan berhitung anak serta media yang digunakan guru dalam proses pembelajaran berhitung. 
Tahap design, peneliti merancang sebuah media permainan melalui aplikasi micrososft powerpoint yang dilengkapi dengan alur cerita keseharian dari seorang tokoh laki-laki yang bernama Mipon. Media ini diberi nama Mipon's Daily yang didalamnya terdapat kegiatan berhitung yang dimulai dari Mipon bangun tidur hingga tidur kembali. Selain itu peneliti juga menyusun indikator kemampuan dan instrumen pengukuran kemampuan berhitung anak usia 5-6 tahun.

Tahap development, peneliti mengembangkan media permainan Mipon's Daily untuk anak usia 5-6 tahun. Selanjutnya, dilakukan uji pakar dari bidang PAUD, media dan bahasa sehingga mendapatkan saran dan masukan mengenai kelayakan media yang dikembangkan. Kemudian peneliti melalukan revisi agar produk dapat diujicobakan ke dalam kelompok kecil dan kelompok besar.

Tahap implementation, peneliti melakukan uji kelompok kecil dan revisi. Kemudian dilanjutkan dengan uji kelompok besar. Sedangkan tahap evaluation, bertujuan untuk mengatasi kendala yang ditemukan saat melakukan uji coba kelompok kecil dan kelompok besar sehingga produk yang dikembangkan dapat dikatakan layak dan efektif digunakan dalam proses pembelajaran.

Penelitian ini dilaksanakan di Kabupaten Lima Puluh Kota, Sumatera Barat. Subjek penelitian adalah anak TK Kelompok B usia 5-6 Tahun. Uji coba kelompok kecil dilaksanakan di TK Raflesia dengan jumlah responden 11 anak. Sedangkan uji coba kelompok besar dilaksanakan di TK Restu Ibu Ketinggian dengan jumlah responden 20 orang anak. Teknik pengumpulan data dalam penelitian ini menggunakan observasi, dokumentasi, wawancara dan catatan lapangan.

\section{HASIL DAN PEMBAHASAN Validasi Pakar}

Penelitian ini melibatkan beberapa pakar untuk menguji kelayakan media yang dikembangkan diantaranya pakar bidang PAUD, media dan bahasa. Secara keseluruhan, ketiga pakar memberikan penilaian persentase sebesar $99 \%$ yang berarti media sangat layak untuk digunakan di lapangan dengan revisi.

\section{Uji Coba Kelompok Kecil}

Uji coba ini dilaksanakan di TK Raflesia pada bulan Desember 2019 dengan jumlah responden 11 orang anak yang berumur 5-6 tahun. Setelah uji coba dilakukan, peneliti mendapatkan hasil bahwa media permainan Mipon's Daily layak digunakan untuk meningkatkan kemamuan berhitung anak dengan catatan pada saat anak bermain sebaiknya peneliti menggunakan speaker agar suara dapat terdengar dengan jelas.

\section{Uji Coba Kelompok Besar (Efektivitas)}

Uji kelompok besar dilaksanakan di TK Restu Ibu Ketinggian dengan jumlah responden 20 orang anak usia 5-6 tahun. Pertama, responden diberikan pretest dengan menggunakan lembar obser yang dibuat oleh peneliti untuk melihat kemampuan berhitung anak sebelum diberikan perlakuan. Selanjutnya anak diberikan perlakuan dengan menggunakan media permainan Mipon's Daily tanpa diberikan penilaian apapun. Setelah itu baru dilaksanakan posttest yaitu penilaian kemampuan berhitung anak setelah diberikan perlakuan.

Analisis data dalam penelitian ini menggunakan program SPSS 16 dengan menghitung uji t-berpasangan (uji paired sample t-test) dengan membandingkan nilai pretest dan posttest untuk mengetahui efektivitas dari produk Mipon's Daily. Berikut ini merupakan tabelnya: 
Tabel 01. Uji Efektivitas pretest dan posttest

Paired Samples Test

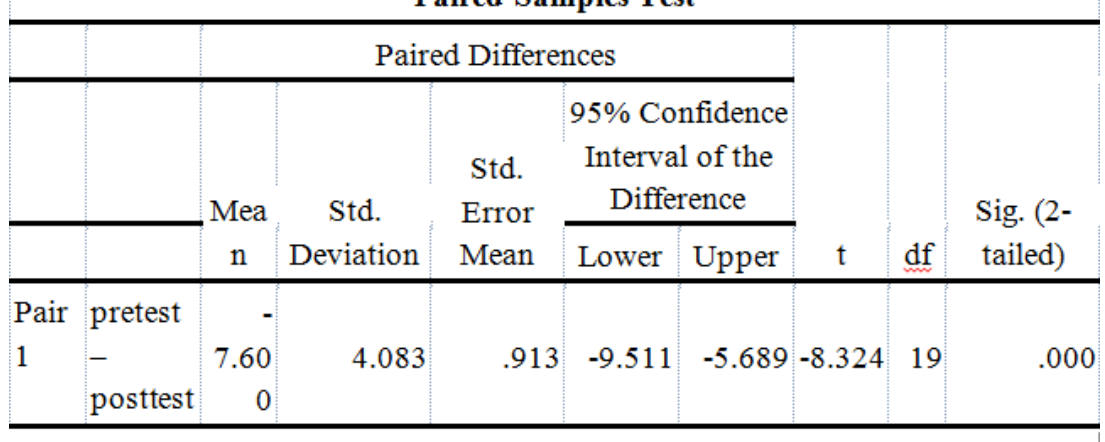

Berdasarkan hasil perhitungan, diperoleh hasil $\mathrm{t}$ hitung sebesar 8.324> dari $\mathrm{t}$ tabel 2.09 dengan nilai signifikansi 0.000 sehingga nilai sig. (2-tailed) $0.000<0,05$. Kemudian untuk confidence interval menunjukkan nilai wilayah adanya perbedaan pada pengenalan di taraf 95\%. Nilai rata-rata pretest sebesar 26.5, sedangkan nilai rata-rata posttest sebesar 34.1. Selisih nilai rata-rata pretest dan posttest sebesar 7.6. Berdasarkan hasil tersebut, maka H0 ditolak dan Ha diterima, sehingga dapat disimpulkan bahwa penggunaan media permainan Mipon's Daily berbasis powerpoint efektif digunakan untuk meningkatkan kemampuan berhitung anak usia 5-6 tahun.

\section{Pembahasan}

Pengembangan media permainan Mipon's Daily berbasis powerpoint dilakukan dengan tujuan memberikan terobosan baru dalam membantu anak usia 5-6 tahun untuk meningkatkan kemampuan berhitungnya. Keadaan yang terjadi di lapangan, menggambarkan bahwa banyak anak yang mengalami masalah dalam berhitung. Hal ini disebabkan karena kurangnya pengetahuan dan kemampuan guru dalam menciptakan media yang kreatif, inovatif dan menarik bagi anak. Seharusnya, pembelajaran yang diberikan pada anak usia dini menggunakan metode playful learning yaitu kegiatan pembelajaran yang menyenangkan melalui permainan (Zosh et al., 2017). Sejalan juga dengan penelitian dari (Colliver \& Nikolay Veraksa, 2019) yang menyatakan bahwa permainan sangat diperlukan oleh anak usia dini untuk memaksimalkan proses belajarnya. Oleh karena itu, pengembangan media permainan Mipon's Daily berbasis powerpoint sesuai dengan konsep tersebut karena kegiatan berhitung anak dilakukan melalui sebuah media permainan.

Pengembangan media permainan Mipon's Daily berbasis powerpoint dilengkapi dengan alur cerita dari seorang tokoh laki-laki yang bernama Mipon. Mipon melakukan kegiatan berhitung mulai dari bangun tidur hingga tidur kembali. Alur cerita ini disesuaikan dengan aktivitas keseharian anak usia 5-6 tahun. Karena menurut pendapatnya Hapidin, 2015, pp. 45-46 kegiatan matematika dapat dipelajari anak melalui kehidupan sehari-harinya seperti: kegiatan membilang, menjumlah, mengurangi, mengenal angka, membandingkan jumlah, serta menyimpulkan data. Hal ini tergambar dari sikap anak yang mudah memahami alur cerita Mipon ketika bermain karena kegiatan tersebut juga dilakukan anak setiap hari.

Pada saat uji efektivitas, peneliti menemukan bahwa anak-anak terlihat antusias dan bersemangat untuk bermain media permainan Mipon's Daily. Alasannya, menurut guru media permainan ini merupakan sesuatu yang baru bagi anak karena biasanya media digital hanya digunakan untuk menampilkan gambar saja sedangkan media Mipon's Daily ini dilengkapi dengan efek suara dan ilustrasi musik. Sesuai dengan penelitian dari Miller (2018) yang menyebutkan bahwa sebuah aplikasi yang diciptakan secara kreatif dan menghibur mampu memberikan daya tarik yang kuat bagi anak. Selain itu, ilustrasi musik juga menjadi salah satu faktor pendukung ketertarikan anak dalam bermain yang sesuai 
dengan penelitian dari (Ruksenas, 2014) menjelaskan bahwa pembelajaran yang disertai musik mampu membantu keberhasilan anak dalam belajar dan dapat meningkatkan perkembangan kognitif anak.

Selanjutnya, anak-anak yang terlihat sabar dalam menunggu giliran dalam bermain. Mereka tetap memperhatikan layar laptop dan fokus dengan alur cerita yang ditampilkan. Begitu juga, jika ada anak yang kesulitan dalam menghitung jumlah benda, anak-anak yang lain ikut mambantu temannya tersebut. Sikap yang anak-anak tunjukkan tersebut sejalan dengan penelitian dari Arnott (2016) menyebutkan bahwa anak-anak yang bermain dengan menggunakan teknologi secara berkelompok akan menunjukkan banyak perilaku sosial dan interaksi.

Penggunaan media permainan digital mampu merangsang otak anak dalam memecahkan suatu masalah terutama dalam berhitung. Hal ini terlihat ketika anak menjawab pertanyaan dari Mipon, mereka dengan teliti menghitung benda yang ditampilkan di layar sehingga mampu memilih jawaban yang tepat. Perilaku yang dimunculkan anak-anak ini dibuktikan oleh penelitian dari Zomer \& Robin H. Kay (2016) yang mengungkapkan bahwa pembelajaran dengan menggunakan media digital dapat memberikan banyak manfaat positif diantaranya membantu anak berpikir kreatif, meningkatkan kemampuan motorik halus dan mengasah keterampilan matematikanya. Selain itu, penelitian dari Sykes (2017) juga menjelaskan bahwa permainan digital juga memberikan pembelajaran yang bermakna bagi anak.

Keberhasilan media yang dikembangkan sejalan dengan penelitian dari Godfrey \& Joel Mtebe (2018) yang menunjukkan bahwa permainan digital yang dikemas melalui kegiatan belajar yang menyenangkan mampu meningkatkan motivasi anak dalam belajar berhitung. Penelitian lain dari Pei Hwa (2018) juga menyebutkan bahwa pembelajaran yang berbasis game digital lebih efektif dibandingkan dengan pembelajaran yang berbasis kelas tradisional dalam memingkatkan pengetahuan matematika anak. Hal ini membuktikan bahwa setiap guru sebaiknya mampu memanfaatkan teknologi dalam proses pembelajaran agar anak mendapatkan pengalaman belajar yang berbeda dalam belajar berhitung.

\section{SIMPULAN}

Permainan Mipon's Daily merupakan permainan yang dirancang untuk mengembangkan kemampuan berhitung anak usia 5-6 tahun. Berdasarkan hasil uji ahli dari ketiga pakar memberikan penilaian persentase sebesar $99 \%$ yang berarti media sangat layak untuk digunakan di lapangan. Sedangkan berdasarkan penelitian yang telah dilakukan permainan ini efektif untuk mengembangkan kemampuan berhitung anak. Hal ini terlihat hasil uji hipotesis dengan nilai t hitung sebesar 8,324 dengan $t$ tabel sebesar 2,09.

\section{UCAPAN TERIMAKASIH}

Penulis mengucpakan terima kasih kepada TK Restu Ibu Ketinggian karena telah diberikan kesempatan untuk melakukan penelitian dan membantu mengumpulkan data. Penulis juga mengucapkan terima kasih kepada dosen pembimbing yang telah memberikan bimbingan dan masukan guna penyempurnaan penelitian ini. Selanjutnya ucapan terima kasih kepada tim editor jurnal obsesi yang telah memberikan saran dan masukan untuk perbaikan artikel ini.

\section{DAFTAR PUSTAKA}

Arnott, L. (2016). An Ecological Exploration of Young Children's Digital Play: Framing Children's Social Experiences with Technologies in Early Childhood. Early Years (An International Research Journal ISSN), 36(3), 271-288.

https://doi.org/10.1080/09575146.2016.1181049 
Aunio, P. (2019). Early Numeracy Skills Learning and Learning Difficulties - Evidencebased Assessment and Interventions. In Cognitive Foundations for Improving Mathematical Learning (1st ed., Vol. 5). https:/ / doi.org/10.1016/B978-0-12-8159521.00008-6

Aunio, P., \& Riika Mononen. (2017). The effects of educational computer game on lowperforming children' s early numeracy skills - an intervention study in a preschool setting. (Tandfonline) European Journal of Special Needs Education, 6257(December), 1-14. https:/ / doi.org/10.1080/08856257.2017.1412640

B. Ramani, G., Emily N. Daubert, \& Nicole R. Scalise. (2019). Role of Play and Games in Building Children's Foundational Numerical Knowledge. (Elsevier) Journal of Cognitive Foundations for Improving Mathematical Learning, 5, 69-90. https:// doi.org/https:/ / doi.org/10.1016/B978-0-12-815952-1.00003-7

Colliver, Y., \& Nikolay Veraksa. (2019). Learning , Culture and Social Interaction The aim of the game : A pedagogical tool to support young children's learning through play. Learning, Culture and Social Interaction, 21(March), 296-310. https:// doi.org/10.1016/j.lcsi.2019.03.001

Godfrey, Z., \& Joel Mtebe. (2018). Redesigning Local Games to Stimulate Pupils ' Interest in Learning Numeracy in Tanzania. International Journal of Education and Development Using Information and Communication Technology (IJEDICT), 14(3), 17-37.

Gurria Angel. (2015). Programme for International Student Assessment (PISA) Result in Focus. In OECD.

Hapidin. (2015). Asesmen \& Evaluasi Pendidikan Anak Usia Dini (Awaluddin Tjalla, ed.). Jakarta: Lembaga Pengembangan Pendidikan Universitas Negeri Jakarta.

Kementerian Pendidikan dan Kebudayaan. (2018). Peraturan Pemerintah Nomor 2 Tahun 2018 Semakin Memperkuat Pentingnya PAUD dan Dikmas.

Kermani, H. (2018). Computer Mathematics Games and Conditions for Enhancing Young Children's Learning of Number Sense. Malaysian Journal of Learning and Instruction, 14(2), 23-57. https://doi.org/10.32890/mjli2017.14.2.2

Laily, A., Jalal, F., \& Karnadi, K. (2019). Peningkatan Kemampuan Konsep Matematika Awal Anak Usia 4-5 Tahun melalui Media Papan Semat. Jurnal Obsesi : Jurnal Pendidikan Anak Usia Dini, 3(2), 396. https:/ / doi.org/10.31004/obsesi.v3i2.214

Lestariningrum, A., \& Handini, M. C. (2017). Analisis Pengembangan Kecerdasan Logis Matematis Anak Usia 5-6 Tahun Menggunakan Permainan Tradisional. (JPUD UNJ) Jurnal Pendidikan Usia Dini, 11, 215-225. https:// doi.org/https:// doi.org/10.21009/JPUD.112.02

Malapata, E., Wijayaningsih, L., Kristen, U., \& Wacana, S. (2019). Jurnal Obsesi : Jurnal Pendidikan Anak Usia Dini Meningkatkan Kemampuan Berhitung Anak Usia 4-5 Tahun Melalui Media Lumbung Hitung. Jurnal Obsesi: Jurnal Pendidikan Anak Usia Dini, 3(1), 283-293. https://doi.org/10.31004/obsesi.v3i1.183

Miller, T. (2018). Developing numeracy skills using interactive technology in a play-based learning environment. International Journal of STEM Education, 5(1), 39. https:/ / doi.org/10.1186/s40594-018-0135-2

Nisa, L. C. (2012). Pemanfataan Teknologi Informasi Untuk pengembangan Kemampuan Berhitung Anak Usia Dini. Sawwa: Jurnal Studi Gender, 7(2), 91. https:// doi.org/10.21580/sa.v7i2.651

Nuriani, E. B., Soemantri, \& Sutrisno. (2016). Pengaruh Penggunaan Media Microsoftpowerpoint terhadap Kemampuan Kognitif Pada Anak Usia 5-6 Tahun di Taman Kanak-kanak Laboratorium Model Universitas Pontianak. Jurnal Ilmiah Pendidikan Anak Usia Dini, 3.

Pei Hwa, S. (2018). Pedagogical Change in Mathematics Learning : Harnessing the Power of Digital Game-Based Learning. (Tandfonline) Journal of Educational Technology \& Society, 21, 259-276. https://doi.org/https://www.j-ets.net/ETS/journals/21_4/21.pdf 
DOI: $10.31004 /$ obsesi.v4i2.428

Philips Parette, H., Jack J. Hourcade, Nichole M.Boeckmann, \& Craig Blum. (2008). Using microsoft PowerPoint to Support Emergent Literacy Skill Development for Young Children at-Risk or Who Have Disabilities. Early Childhood Education Journal, 36(3), 233-239. https://doi.org/10.1007/s10643-008-0275-y

Raghubar, K. P., \& Marcia A. Barnes. (2016). Early Numeracy Skills in Preschool-Aged Children: a Review of Neurocognitive Findings and Implications for Assessment and Intervention. Clinical Neuropsychologist. https://doi.org/10.1080/13854046.2016.1259387

Rosalind, C., \& Karen K. Lind. (2013). Math and Science for Young Children (7th ed.). USA: Cengage Learning.

Ruksenas, J. (2014). The benefits of Music Classes for Preschoolers: The ABC of DO RE MI. Researchgate Publications, (May).

Suryana, D. (2018). Pendidikan Anak Usia Dini (Stimulasi \& Aspek Perkembangan Anak. Indonesia: Prenada Media.

Sykes, J. M. (2017). Digital games and language teaching and learning. (December), 219-224. https://doi.org/10.1111/flan.12325

Zomer, N. R., \& Robin H. Kay. (2016). Technology Use in Early Childhood Education : A Review of Literature Technology Use in Early Childhood Education : A Review of Literature. (March).

Zosh, J. M., Emily J. Hopkins, Hanne Jensen, Claire Liu, Dave Neale, Kathy Hirsh-Pasek, ... David Whitebread. (2017). Learning through play: a review of the evidence. The LEGO Foundation. 